\title{
Design Analysis and Performance Evaluation of a Novel Multi-Cantilever Foil Bearing
}

\author{
M. Obaseki ${ }^{\mathrm{a}, *}$, P. T. Elijah ${ }^{\mathrm{a}}$, P. B. Alfred ${ }^{\mathrm{b}}$ \\ ${ }^{a}$ Applied Mechanics and Design / Production Research Group, Department of Mechanical Engineering, Faculty of \\ Engineering, Nigeria Maritime University, Okerenkoko, Delta State, NIGERIA. \\ ${ }^{b}$ Department of Mechanical Engineering, Faculty of Engineering, University of Port Harcourt, Port Harcourt, \\ Rivers State, NIGERIA.
}

\begin{abstract}
This study gives an explanation to design analysis and performance evaluation of a novel multi-cantilever foil bearing (MCFB). The aim of this study is to develop a theoretical model that will explain the working principles of the cantilever foil bearing. A theoretical derivation of structural and vibration models were developed to find structural stiffness, equivalent viscous damping and maximum deflection. Findings show that the theoretical results of structural models have an equivalent structural stiffness of $58.59 \mathrm{kN} / \mathrm{mm}$, equivalent viscous damping of $0.599 \mathrm{kNs} / \mathrm{m}$ and maximum deflection of $0.5675 \mathrm{~mm}$. The equivalent viscous damping is computed at a near zero circumferential coordinate (0.0350). The results obtained from vibration models show an equivalent structural stiffness of $58.74 \mathrm{kN} / \mathrm{mm}$, equivalent viscous damping of $0.228 \mathrm{kNs} / \mathrm{m}$ and maximum deflection of $0.5675 \mathrm{~mm}$. Theoretical viscous damping coefficient varies from $0.23 \mathrm{kNs} / \mathrm{m}$ at $24 \mathrm{~Hz}$ to $0.026 \mathrm{kNs} / \mathrm{m}$ at $200 \mathrm{~Hz}$ when determined at maximum deflection of $0.5675 \mathrm{~mm}$ and phase angle of 0.0350 . This means the higher the frequency, the lower the viscous damping coefficient. The validation was done over frequency range $24-200 \mathrm{~Hz}$ and at amplitude of $50 \mathrm{~mm}$ at a 450 phase angle. The models were found to have compared well with experimental results in the prediction of equivalent viscous damping coefficient. The models can be relied upon to analyze the behaviour of MCFB and it can also form a theoretical background for the design and manufacture of Multi-Cantilever Foil Bearing.
\end{abstract}

Keywords: foil bearing, structural model, vibration model, equivalent viscous damping, structural stiffness, maximum deflection

\section{INTRODUCTION}

Foil bearing (FB) are mostly used in high-speed performance turbo-machines [1]. They have sheet of foil metals made of mainly steel. Foil bearing are hydrodynamic self-acting bearing capable of accommodating misalignment, reduces surfaceto-surface contact, and have splendid damping coefficient [2]. Foil bearing can be grouped into Gas Foil Bearings (GFB), Viscoelastic Foil Bearing, Multi-wound Foil Bearing, Metal Mesh Foil Bearing and the Multi-cantilever Foil Bearing (MCFB). The gas foil bearing comes with either single bump foil or double bumps foil which is the major determinant of the bearing structural stiffness and damping performances.

GFBs are used in oil free turbo machinery and high temperature applications which include but not limited to aircraft cycle machines, gas compressors and micro turbines [3, 4]. Viscoelastic foil bearing, metal mesh bearing and multicantilever foil bearing are gas foil bearing with

\footnotetext{
${ }^{*}$ Corresponding author (Tel: +234(0) 803767 0948)

Email addresses: martins.obaseki@nmu.edu.ng (M. Obaseki), paul.elijah@nmu.edu.ng (P. T. Elijah), peter.alfred@yahoo.com (P. B. Alfred)
}

special modification of its components to enhance the overall performance of the bearing structural stiffness and viscous damping. GFBs have some features which make them more advantageous than the other bearings and shaft support systems. Some of such features according to Serdar [5] are: it does not require oil lubrication and as such requires no scheduled maintenance. it is environmentally sustainable and performs excellently in both low and high speed and temperature operations.

The viscoelastic foil bearing was proposed by Hou et al. [6]. In an attempt to achieve uniform structural stiffness and viscous damping, the bump foil was replaced by the viscoelastic materials which then gave the bearing a good stability. The metal mesh gas foil bearing was proposed in 2008 by Lee and Kim [7], and its structural stiffness and damping coefficient test measured by Luis and Thomas in 2010 [8-10]. The structural difference of this bearing from the conventional GFB is the presence of porous metal mesh foil strips which serve as a replacement of bump foils of GFB. The multi-wound foil bearing was first worked on by Feng and Kaneko [11, 12]. Recent 
researches are on-going on Gas Foil Bearings to improve its advantages in aeronautics and power industries [8]. The targeted advantages are low power loss, misalignment accommodation, stability and particles resistance.

The novel Multi-cantilever Foil Bearing (MCFB) was first reported by Feng et al. [13]. The novel prototype MCFB has a top foil made of viscoelastic material which has direct contact with the shaft, three foil strips with array of cantilevers. Figure 1 shows the schematics of prototype MCFB developed and tested by Feng et al. [13].

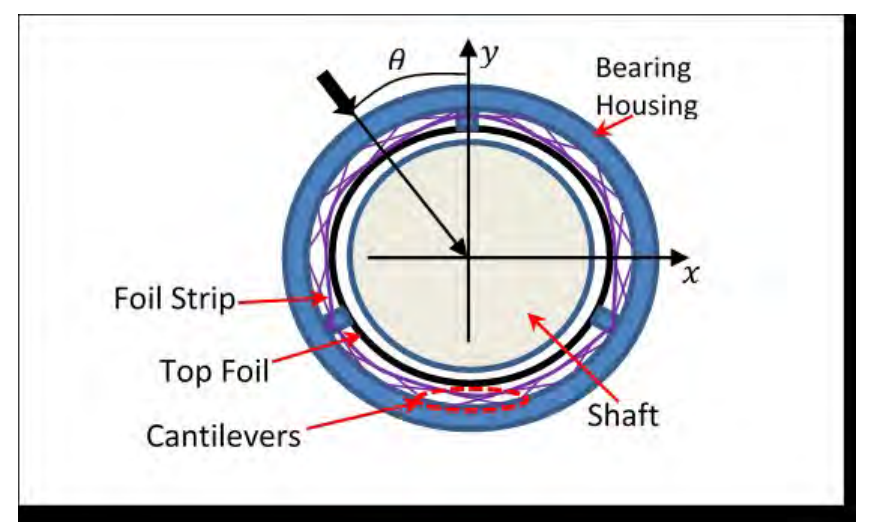

Figure 1: Schematics of Cantilever Foil Bearing [13].

The MCFB of Feng et al. [13] has two end caps and main bearing housing. The arrangement of cantilevers on each foil strip is such that one end of each cantilever is fixed into a slot on to thefoil strips while the other end called the "free end" is on the bearing housing. The aim of the slots is to guide each cantilever sliding motion during loading and offloading and to reduce their structural stiffness. The foil strips are not fixed but form compliant foundation for the bearing surface. Obaseki and Alfred [14] modeling and investigating the effect of offset distance on slider-crank mechanism.

Feng et al. [13] performed an experimental analysis to investigate the behaviour and the performance of the multi-cantilever foil bearing in terms of structural stiffness, viscous damping and deflection pattern. However, there is no theoretical and mathematical model yet to further explain the working principles of the bearing, hence, this work. The aim of this work is to develop a theoretical model to explain the working principles of the cantilever foil bearing in order to get structural stiffness, equivalent viscous damping and maximum deflection. To achieve this, theoretical modeling of the MCFB based on the structure and vibration of the bearing system (subject to harmonic loading), validation and analysis of the models will be tested with experimental data.

\section{DESIGN ANALYSIS OF MULTI- CANTELEVER FOIL BEARING}

Analysis of a novel Multi-Cantilever Foil Bearing (MCFB) is necessary to ascertain its com- pliance with bearing design standard. Theoretical design analysis of the MCFB is to determine the deflection and vibration of cantilevers bearing structure when subjected to fluctuating load and to have theoretical backup for future design implementation.

\subsection{Structural Design}

To carry out structural design, it was assumed that there is uniform pressure in the bearing and that each cantilever has uniform stiffness. A novel Multi-Cantilever Foil Bearing (MCFB) has three equal foil strips, each fitted with 60 cantilevers, arranged in array of $5 \times 12$ cantilevers. And because the foil strips are not fixed, the structural stiffness of the bearing is assumed solely as the stiffness of the cantilevers.

Figure 2 shows the position of the cantilever when it is under pressure load. The dotted horizontal line shows the no load position of the cantilever. When loaded, the free ends of the cantilevers slide away from the original (no load) position and the cantilevers deflect through a distance, $x$. Figure 3 shows the deflection of a single cantilever as its response to load, $R$, which is the reaction equivalent of the effect of the pressure force in the bearing.

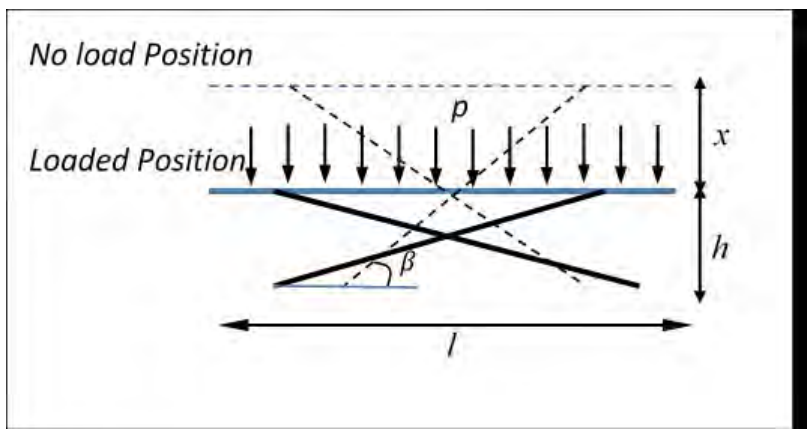

Figure 2: Deflection of Loaded Cantilever Bearing.

Let: $l_{c}=$ Length of Cantilever $[\mathrm{mm}] ; l_{f}=$ Length of foil strip[mm]; $b_{f}=$ Breadth of foil strip[mm]; $\mathrm{p}=$ Point Pressure in the bearing $[\mathrm{Pa}] ; \beta=$ Incline angle of Cantilever at no load [Rad]; $R=$ Normal Reaction at the free end of Cantilever[N]

\subsubsection{Load and Reaction on cantilever}

The load on one foil strip is the product of pressure, $p$, and the total surface area, $A$, of the strip.

$$
F=p A=p l_{f} b_{f}
$$

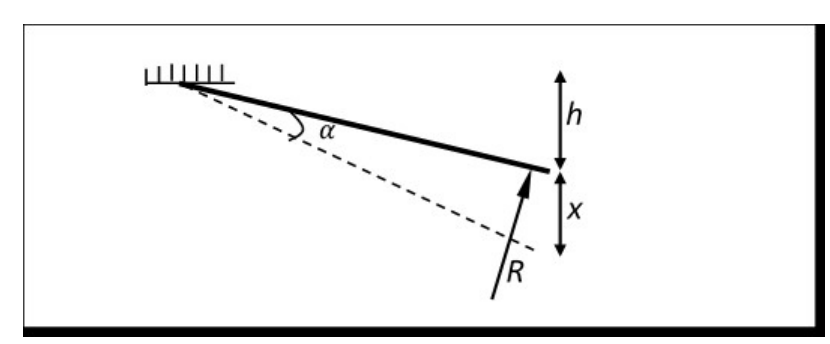

Figure 3: Deflection of Single Cantilever. 
There are 60 cantilevers on each foil strip, therefore, the load on each cantilever is the total load divided by 60 as given by Eq. (2).

$$
F_{c}=\frac{p l_{f} b_{f}}{60}
$$

According to Newton's law, action and reaction are always equal; therefore, the normal reaction at the free end of the cantilever is given as;

$$
R=F_{c} \cos \beta=\frac{p l_{f} b_{f} \cos \beta}{60}
$$

\subsubsection{Deflection and stiffness of cantilever}

Let $E=$ Elastic Modulus of Cantilever[GPa]; $I=$ Moment of inertia of Cantilever $\left[\mathrm{Kgm}^{2}\right]$ $\alpha=$ Deflection angle of Cantilever at maximum load [Rad]

$x=$ Deflection of Cantilever at maximum load [m] The moment of inertia of the cantilever of rectangular section with thickness, $t_{c}$ and breadth, $b_{c}$, is given as; $[15,16]$

$$
I=\frac{b_{c} t_{c}^{3}}{12}
$$

The maximum deflection of the cantilever is given as;

$$
x=\frac{R L_{c}^{3}}{3 E I}
$$

The maximum deflection angle is given as;

$$
\alpha=\frac{R L_{c}^{2}}{2 E I}
$$

The stiffness, $k$, of the cantilever is the load on each cantilever divided by deflection and is given by Beléndez et al. [15] as;

$$
k=\frac{R}{x}=\frac{3 E I}{L_{c}^{3}}
$$

The foil strip stiffness was neglected because the foil strip thickness is very small $(0.1 \mathrm{~mm})$ and as such, the stiffness is small and negligible compare to the overall structural stiffness of the cantilevers. Therefore, the equivalent Structural Stiffness, $K_{e q}$, for each foil strip-Cantilever arrangement made of 60 cantilevers is calculated from the structure of the bearing as equivalent structural stiffness of parallel arrangement and given in Eq. (7b) as;

$$
k_{e q}=60 k=\frac{180 E I}{L_{c}^{3}}
$$

\subsection{Torque and Load on Cantilever Bearing}

Let: $c=$ Clearance between shaft and bearing $[\mathrm{mm}] ; \quad t=$ time $[\mathrm{s}] ; \quad N=$ Shaft rotation [Rev/min]; $L=$ Bearing Length $[\mathrm{mm}] ; r=$ Radius of rotor journal $[\mathrm{mm}] ; P_{a}=$ Atmospheric Pressure
$[\mathrm{Pa}] ; e=$ Eccentricity $[\mathrm{mm}] ; \theta=$ Circumferential coordinate [rad].

Let $z, \omega$ and $\theta$ be defined as;

$$
z= \pm \frac{L}{2} ; \omega=2 \pi f=\frac{\pi N}{30} ; \theta=\omega t
$$

Again, the following parameters can be written in a dimensionless form as;

$$
\dot{z}=\frac{2 z}{L} ; \dot{p}=\frac{p}{p_{a}} ; \dot{t}=N t ; \dot{x}=\frac{x}{c}
$$

\subsubsection{Equivalent damping coefficient}

Assuming there is uniform pressure on the bearing strip surfaces, the dimensionless point pressure is given by the formula [17];

$$
\dot{p}-1=\frac{k c \hat{x}}{p_{a} l}+\frac{C_{1} N}{p_{a}} \frac{\partial \dot{x}}{\partial \dot{t}}
$$

Where $C_{1}=$ Equivalent damping coefficient of each cantilever $[\mathrm{Ns} / \mathrm{m}]$ and $l=\frac{l_{f}}{5}$, $k=$ stiffness of the cantilevers $[\mathrm{N} / \mathrm{m}]$

$l=$ length of foil strip part occupied by one cantilever

$$
C_{1} \frac{\partial \dot{x}}{\partial \dot{t}}=\frac{p_{a}}{N}\left[(\dot{p}-1)-\frac{k c \dot{x}}{p_{a} l}\right]
$$

$C_{1}$ can be determined by taking the direct integral of Eq. (11) as;

$$
C_{1}=\frac{1}{\dot{x}} \int_{0}^{t} \frac{P_{a}}{N}\left[(\dot{p}-1)-\frac{k c \dot{x}}{p_{a} l}\right] \partial \dot{t}
$$

At $\dot{t}=0, C_{1}=0$.

$$
C_{1}=\frac{\dot{t}}{\dot{x}} \frac{P_{a}}{N}\left[(\dot{p}-1)-\frac{k c \hat{x}}{p_{a} l}\right]
$$

Substituting $\frac{l_{f}}{5}$ for, changing to dimensional form and simplifying gives;

$$
C_{1}=\frac{\hat{t} c}{N}\left[\left(\frac{p-p_{a}}{x}\right)-\frac{5 k}{l_{f}}\right]
$$

Substituting $\frac{\theta}{\omega}$ for $t$ and $\dot{t}=N t$ into Eq. (14) gives; Therefore, the equivalent viscous damping is given as;

$$
C_{1}=\frac{\theta_{c}}{\omega}\left[\left(\frac{p-P_{a}}{x}\right)-\frac{5 k}{l_{f}}\right]
$$

$C_{1}$ is a function of pressure difference per unit deflection in the bearing, the structural stiffness per unit length of the foil strip-cantilever system and the clearance between the shaft and the bearing inner surface. The Equivalent Viscous Damping, $C_{e q}$, for each foil strip-Cantilever arrangement made of 60 cantilevers is calculated from the structure of the bearing as the equivalent viscous damping coefficient in parallel arrangement of 60 dampers as in Eq. (15b).

$$
C_{e q}=60 C_{1}=\frac{60 \theta_{c}}{\omega}\left[\left(\frac{p-P_{a}}{x}\right)-\frac{5 k}{l_{f}}\right]
$$




\subsubsection{Bearing load capacity and reaction torque}

According to Tim et al. [18], the rotor model is used to determine the non-dimensional load capacity and reaction torque. This involves integrating the uniform pressure in the bearing over each strip.

\section{Load capacity}

The non-dimensional load capacity in the $\mathrm{x}$ direction is given as;

$$
\dot{F}_{x}=-\int_{-1}^{1} \int_{0}^{\frac{2 \pi}{3}}(\dot{p}-1) \sin \theta d \theta d \dot{z}
$$

The non-dimensional load capacity in the ydirection is given as;

$$
\dot{F}_{y}=-\int_{-1}^{1} \int_{0}^{\frac{2 \pi}{3}}(\dot{p}-1) \cos \theta d \theta d \dot{z}
$$

The non-dimensional load capacity of the bearing is given as;

$$
\dot{F}_{L}=\sqrt{\dot{F}_{x}^{2}+\dot{F}_{y}^{2}}
$$

The dimensional equivalent of load capacity of the bearing is given by Liu et al. [17] as;

$$
\dot{F}_{L}=\frac{3}{2} \hat{F}_{L} P_{a} r L
$$

Where $L=$ Length of bearing and $r=$ Inner radius of bearing

\section{Reaction moment}

The non-dimensional reaction moment in the $\mathrm{x}$ direction is given by Liu et al. [17] as;

$$
\dot{M}_{x}=-\int_{0}^{2} \dot{z} \int^{\frac{2 \pi}{3}}(\dot{p}-1) \cos \theta d \theta d \dot{z}
$$

The non-dimensional reaction moment in the $\mathrm{y}$ direction is given as;

$$
\dot{M}_{y}=-\int_{0}^{2} \dot{z} \int^{\frac{2 \pi}{3}}(\dot{p}-1) \sin \theta d \theta d \dot{z}
$$

The non-dimensional reaction moment of the bearing is given as;

$$
\dot{M}=\sqrt{\dot{M}_{x}^{2}+\dot{M}_{y}^{2}}
$$

The dimensional equivalent of reaction moment of the bearing is given by Liu et al. [17] as;

$$
M=\frac{5}{4} \dot{M}_{a} c r L^{2}
$$

\subsection{Vibration Analysis}

The cantilever bearing has three disjointed foil strips. Each of the foil strips is supported by sixty cantilevers. Each foil strip cantilever assembly vibrates in tune with the excitation force. Since there is uniform pressure in the bearing, the vibration of each foil strip-cantilever assembly represents the vibration of the entire system.

Given that the bearing is subjected to a harmonic excitation force, it will vibrate in accordance with the equation;

$$
M \ddot{x}+C_{e} \dot{x}+K_{e} x=F t
$$

Where, $C_{e}=$ Equivalent viscous damping for all the cantilevers in one foil strip, $K_{e}=$ Equivalent Structural Stiffness of the entire cantilever in one foil strip, $M=$ Vibrating mass (Mass of 60 cantilevers and one foil strip). Figure 4 shows the schematics of the actual geometry of a single foil strip with cantilevers. This shows uniform pressure transmitted to the foil strip through the viscoelastic top foil. Figure 5 shows the approximated system which behaves the same way as the system in Fig. 4. Figure 5 was further reduced to Fig. 6 for easy analysis. Figure 6 shows the equivalent structural stiffness, load and viscous damping in one foil strip.

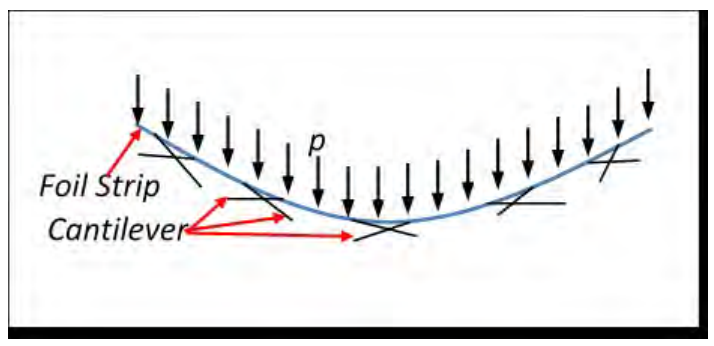

Figure 4: Foil Strip and Cantilever Actual Orientation.

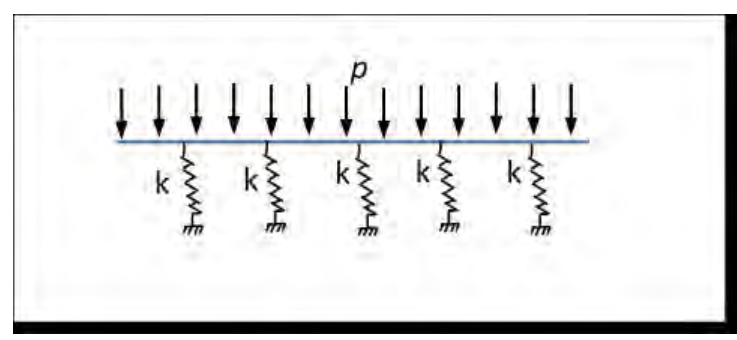

Figure 5: Foil Strip and Cantilever Approximate Orientation.

The harmonic excitation force could be cosine function or complex exponent function.

\subsubsection{Solution by cosine function}

Let $F(t)=F \cos \omega t$, where $\omega=$ single excitation frequency, then, the steady state solution, $x_{s}$, is in the form [19];

$$
x_{s}=A \sin (\omega t)+B \sin (\omega t)
$$




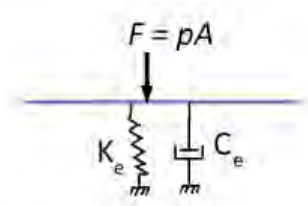

Figure 6: Equivalent Stiffness, Load and Viscous Damping.

Differentiating Eq. (25) to obtain the first derivative $\dot{x}_{s}$ and the second derivative $\dot{x}_{s}$ and substituting into Eq. (24) gives;

$$
\begin{aligned}
& \left(K_{e}-M \omega^{2}\right)(A \sin \omega t+B \cos \omega t)+C_{e} \omega(A \cos \omega t-B \sin \omega t) \\
& =F \cos \omega t
\end{aligned}
$$

Equating the coefficients of $\sin \omega t$ and $\cos \omega t$ in both sides of Eq. (26) and solving the two resultant equations simultaneously gives;

$$
\begin{aligned}
& A=\frac{F C_{e} \omega}{\left(K_{e}-M \omega^{2}\right)^{2}+\left(C_{e} \omega\right)^{2}} \\
& A=\frac{F\left(K_{e}-M \omega^{2}\right)}{\left(K_{e}-M \omega^{2}\right)^{2}+\left(C_{e} \omega\right)^{2}}
\end{aligned}
$$

Let ; $X=\sqrt{A^{2}+B^{2}}$

Then, the steady state solution can also be represented as;

$$
x_{s}=X \sin (\omega t-\varnothing)
$$

Where; $\varnothing=$ Phase angle. Evaluating $X$ from Eq. (27a) as $X=\sqrt{\left(A^{2}+B^{2}\right)}$ gives;

$$
X=\frac{F}{\sqrt{\left(K_{e}-M \omega^{2}\right)^{2}+\left(C_{e} \omega\right)^{2}}}
$$

And $\tan \varnothing=\frac{A}{B}$

$$
\varnothing=\tan ^{-1}\left(\frac{C_{e} \omega}{K_{e}-M \omega^{2}}\right)
$$

\subsubsection{Solution by complex exponential function}

Let $F(t)=F \exp ^{i \omega t}$, where $i=$ complex number. [19];

The steady state solution will take the form

$$
x_{s}=X \exp ^{i(\omega t-\varnothing)}
$$

Differentiating Eq. (31) to obtain $\dot{x}_{s}$ and $\ddot{x}_{s}$ and substituting into Eq. (24) gives;

$$
\left[\left(K_{e}-M \omega^{2}\right)+i \omega C_{e}\right] X \exp ^{i(\omega t-\varnothing)}=F \exp ^{i \omega t^{L}}
$$

From which;

$$
\left(K_{e}-M \omega^{2}\right)+i \omega C_{e}=\frac{F}{X} \exp ^{i \varnothing}
$$

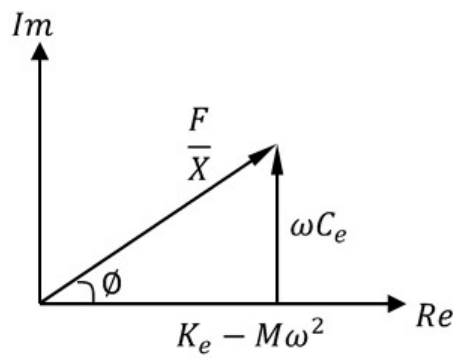

Figure 7: Complex Diagram.

Equation (33) can be represented on a complex diagram as shown in Fig. 7 .

From the diagram, we have;

$$
X=\frac{F}{\sqrt{\left(K_{e}-M \omega^{2}\right)^{2}+\left(C_{e} \omega\right)^{2}}}
$$

and

$$
\varnothing=\tan ^{-1}\left(\frac{C_{e} \omega}{K_{e}-M \omega^{2}}\right)
$$

Equations (29) and (30) obtained from harmonic excitation of cosine function are exactly the same as Eqs. (34) and (35) obtained from harmonic excitation of complex exponential function. Since the results are the same, the equivalent structural stiffness and viscous damping can be obtained from the analysis the vibration coming from harmonic excitation of complex exponential function. This is done by separating and equating the real and imaginary part of Eq.(33), and then making $K_{e}$ and $C_{e}$ the subject of the formulas as in Eqs. (36) and (37).

$$
\begin{gathered}
K_{e}=M \omega^{2}+R e\left(\frac{F}{X} \exp ^{i \varnothing}\right) \\
C_{e}=\frac{\operatorname{Im}\left(\frac{F}{X} \exp ^{i \varnothing}\right)}{\omega}
\end{gathered}
$$

Where $R e\left(\frac{F}{X} \exp ^{i \varnothing}\right)=$ real part of $\left(\frac{F}{X} \exp ^{i \varnothing}\right)$ and $\operatorname{Im}\left(\frac{F}{X} \exp ^{i \varnothing}\right)=$ imaginary part of $\left(\frac{F}{X} \exp ^{i \varnothing}\right)$.

\section{4.,}

Determination of Cantilever Angle The cantilever angle, $\beta$ is determined from the data in Table 1 . The cantilever vertical height, $h$, is half of the difference between bearing housing inner diameter and the top foil outer diameter. The outer diameter of the top foil, $D_{f}$ is the difference between the top foil inner diameter and twice the top foil thickness. The perpendicular distance between the foil strip and the bearing housing inner surface at no load condition is derived from the geometry of the bearing as;

$$
h=\frac{1}{2\left[D_{h}-D_{f}\right]}
$$




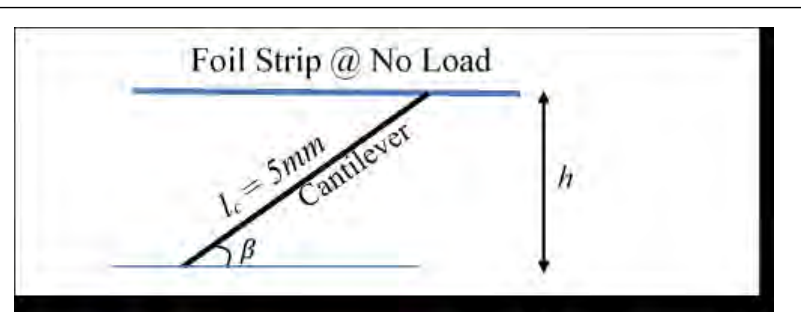

Figure 8: Cantilever-foil strip Orientation.

where $D_{h}=$ Bearing Housing inner diameter and $D_{f}=$ outer diameter of the top foil.

Since, the foil strip thickness was not used in the determination of the structural stiffness and viscous damping coefficient; it was also ignored in the calculation of cantilever angle.

From Fig. 8, the cantilever angle is given as;

$$
\beta=\sin ^{-1}\left(\frac{h}{l_{c}}\right)
$$

The vibrating mass, $M$, is computed from the density of the material of the cantilevers.

$$
M=\rho V
$$

Where, $V=$ Volume of 60 cantilevers and the foil strip and $\beta=$ density

\section{RESULTS AND DISCUSSION}

Performance evaluation was carried out from theoretical structural model and vibration model developed in this work. Data of prototyped MCFB fabricated and tested by Feng et al. [13] was used to carry out this analysis and to validate the developed models. MATLAB 2014 software was used to carry out the calculations and all the plots. MATLAB Scripts were written, tested and debugged to eliminate errors, then used to performed all computations and performance analysis.

\subsection{Input Data for Analysis}

The input data for analysis was obtained from the prototype Novel Multi-Cantilever Foil Bearing (MCFB) fabricated by Feng et al. [13]. The data are in Table 1.

\subsection{Output of Structural Models}

The structural models were used for the determination of the Multi-Cantilever Foil Bearing parameters from structural analysis. Structural models here specifically mean Eq. (4) - (7b) and (15b). MATLAB Software was used to develop a script to handle the computation. The data in Table 1 was used as input data for the script and the output is in Table 2. A concentrated load of $100 \mathrm{~N}$ have been the only source of pressure in the bearing, thus the load on one strip is one-third of the concentrated load on the bearing. The results of structural models show an equivalent structural stiffness of $58.59 \mathrm{kN} / \mathrm{mm}$, equivalent viscous damping of $0.599 \mathrm{kNs} / \mathrm{m}$ and maximum deflection of $0.5675 \mathrm{~mm}$. The equivalent viscous damping is calculated at a near zero circumferential coordinate $(0.0350)$.

\begin{tabular}{|c|c|c|c|}
\hline $\mathbf{S} / \mathbf{N}$ & Parameter & Value & Unit \\
\hline 1 & Bearing Axial Length & 26 & $\mathrm{~mm}$ \\
\hline 2 & Top Foil Inner Diameter & 32 & $\mathrm{~mm}$ \\
\hline 3 & $\begin{array}{l}\text { Bearing Housing inner } \\
\text { Diameter }\end{array}$ & 33.3 & $\mathrm{~mm}$ \\
\hline 4 & Top Foil Thickness & 0.3 & $\mathrm{~mm}$ \\
\hline & Rotor Shaft Diameter & 31.95 & $\mathrm{~mm}$ \\
\hline 6 & Diametral Clearance & 0.05 & $\mathrm{~mm}$ \\
\hline 7 & Foil Strip Thickness & 0.1 & $\mathrm{~mm}$ \\
\hline 0 & Foil Strip Length & 31 & $\mathrm{~mm}$ \\
\hline 10 & Foil Strip Width & 26.05 & $\mathrm{~mm}$ \\
\hline 11 & Cantilever Length & 5 & $\mathrm{~mm}$ \\
\hline 12 & Cantilever Width & 1.25 & $\mathrm{~mm}$ \\
\hline 13 & Elastic Modulus of Cantilever & 200 & GPa \\
\hline 14 & Number of Foil Strips & 3 & 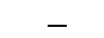 \\
\hline 16 & $\begin{array}{l}\text { Number of Cantilever on each } \\
\text { foil strip }\end{array}$ & 60 & - \\
\hline 17 & Density of Cantilever Material & 7850 & $\mathrm{Kg} / \mathrm{m}^{3}$ \\
\hline 18 & Atmospheric Pressure & 101325 & \\
\hline
\end{tabular}

Table 1: Input Data for Analysis.

Table 2: Output of Structural Models.

\begin{tabular}{lccc}
\hline S/N & Parameter & Value & Unit \\
\hline 1 & Structural Stiffness & 58.5937 & $\mathrm{kN} / \mathrm{mm}$ \\
2 & Equivalent Viscous Damping & 0.5994 & $\mathrm{kNs} / \mathrm{m}$ \\
3 & Maximum Deflection & 0.5675 & $\mathrm{~mm}$ \\
4 & Deflection Angle & $1.7 \mathrm{e}-4$ & $\mathrm{rad}$ \\
5 & Volume of Vibrating Matter & $5.46 \mathrm{e}-7$ & $\mathrm{~m}^{3}$ \\
6 & Vibrating Mass & 0.0043 & $\mathrm{Kg}$ \\
7 & Load Capacity & 126.48 & $\mathrm{~N}$ \\
8 & Reaction Moment & $8.24 \mathrm{e}-5$ & $\mathrm{Nm}$ \\
\hline
\end{tabular}

\subsection{Output of Vibration Models}

The vibration models were used for the determination of the Multi-Cantilever Foil Bearing parameters from vibration analysis. Vibration models are defined in Eqs. (24) and (34) - (37). A script developed in MATLAB was used to handle the calculation. A concentrated load of $100 \mathrm{~N}$ (used as an equivalent of uniformly distributed load within the bearing) and the data in Table 1 was used as input data for the MATLAB script and the output is in Table 3. The computation was done at a near zero phase angle. The results obtained from vibration models show an equivalent structural stiffness of $58.74 \mathrm{kN} / \mathrm{mm}$, equivalent viscous damping of $0.228 \mathrm{kNs} / \mathrm{m}$ and maximum deflection of $0.5675 \mathrm{~mm}$.

Table 3: Output of Vibration Models.

\begin{tabular}{lccc}
\hline S/N & Parameter & Value & Unit \\
\hline 1 & Structural Stiffness & 58.7369 & $\mathrm{kN} / \mathrm{mm}$ \\
2 & Equivalent Viscous Damping & 0.2284 & $\mathrm{kNs} / \mathrm{m}$ \\
3 & Maximum Deflection & 0.5675 & $\mathrm{~mm}$ \\
4 & Natural Frequency & $1.17 \mathrm{e} 5$ & $\mathrm{~Hz}$ \\
5 & Critical Damping Coefficient & 0.2273 & - \\
6 & Force Transmissibility & $1.80 \mathrm{e}-6$ & - \\
7 & Vibration Force & $1.24 \mathrm{e}-5$ & $\mathrm{~N}$ \\
8 & Work Done Per Cycle & $3.63 \mathrm{e}-8$ & $\mathrm{~J}$ \\
\hline
\end{tabular}


Table 4: Comparison of Structural and Vibration Models.

\begin{tabular}{lcccc}
\hline S/N & Parameter & Vibration & Structural Models (S) & Structural Models (S) \\
\hline 1 & Structural Stiffness $(\mathrm{KN} / \mathrm{mm})$ & 58.7369 & 58.5937 & 0.1432 \\
2 & Equivalent Viscous Damping $(\mathrm{KNs} / \mathrm{m})$ & 0.2284 & 0.5994 & -0.371 \\
3 & Maximum Deflection $(\mu \mathrm{m})$ & 0.5675 & 0.5675 & 0 \\
\hline
\end{tabular}

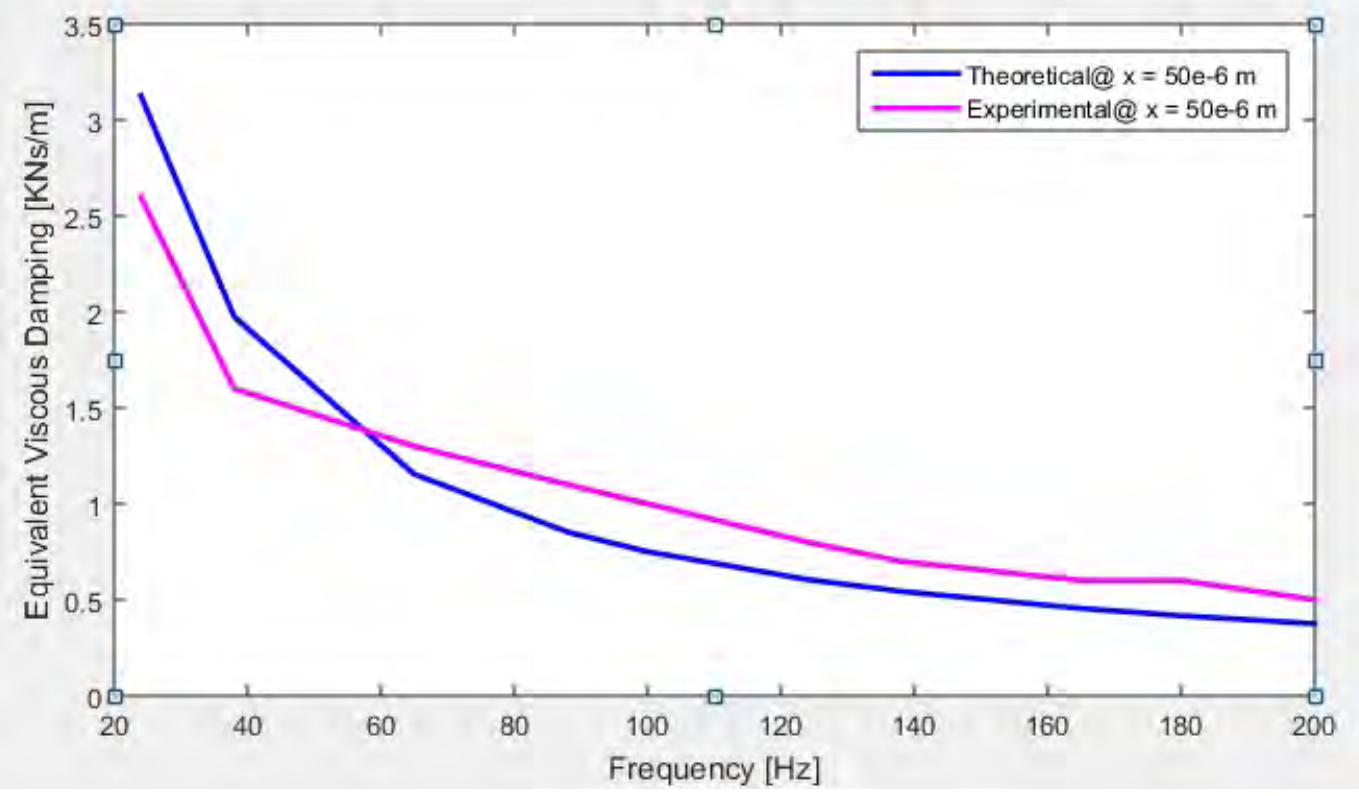

Figure 9: Validation of Equivalent Viscous Damping with Experimental values.

\subsection{Comparison of the two Models}

Table 4 shows the comparison between the output values of structural models and vibration models. The models are in agreement especially in the determination of structural stiffness and maximum deflection.

\subsection{Validation of Stiffness and Viscous Damping Models}

To validate the stiffness and viscous damping vibration models, experimental values of Feng et al. [13] were used. The validation was done over frequency range $24-200 \mathrm{~Hz}$ together with the data in Table 1 and at amplitude of $50 \mathrm{~mm}$ and at 450 phase angle. The equivalent viscous damping coefficient and the structural stiffness of this work were compared with the experimental data. The results are shown on plots in Fig. 9 and Fig. 10.

The plot in Fig. 9 shows a reasonable level of agreement between the experimental values and theoretical values of this model. Figure 10 shows very little agreement; this is due to the assumption of uniform stiffness of the cantilever. The assumption was necessary to eliminate ambiguity and complexity in the modeling process. The theoretical models show a constant structural stiffness over the range of frequencies under consideration, whereas the prototypes MCFB have non-uniform stiffness. The free ends of the actual cantilevers have low stiffness and as such the stiffness varies non-uniformly with frequency.

\subsection{MCB Deflection and Bearing Load}

The factors affecting deflection and their effects were analyzed. The cantilever angle determines the deflection of the cantilever. Figure 11 shows that defection is maximum at a near zero cantilever angle and zero at cantilever angle of 900 . At 900 the cantilever is parallel to the direction of loading and cannot deflect rather it deforms. Cantilever angle cannot be zero because at zero it lies parallel to the foil strip; thus, it will be restricted from deflecting. A cantilever angle of 40 was a good choice for the MCFB as it allows for maximum deflection.

Figure 12 shows a linear relation between load and deflection. The higher the load the higher the deflection. Since maximum deflection cannot be equal or exceed $0.35 \mathrm{~mm}$ as determined from Fig. 8 , a load that can cause a deflection of $0.3 \mathrm{~mm}$ becomes the critical load and must be avoided. Load-deflection curve can be used to determine the MCFB maximum bearing load.

\subsection{Vibration Analysis}

Vibration analysis is aimed at determining the conditions that influence the structural stiffness, equivalent viscous damping and the amplitude of vibration. Figures 13,14 and 15 show the effect of frequency on the equivalent structural stiffness, equivalent viscous damping and the amplitude of vibration (Displacement of vibrating mass). 


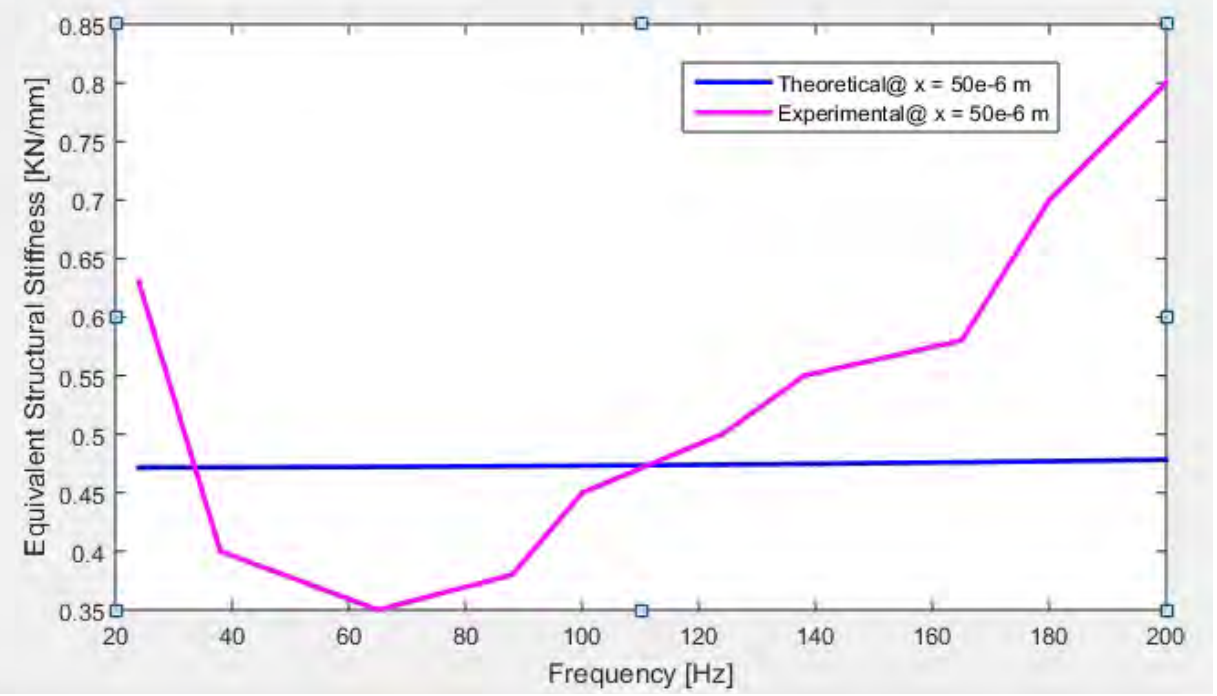

Figure 10: Validation of Equivalent Structural Stiffness with Experimental values.

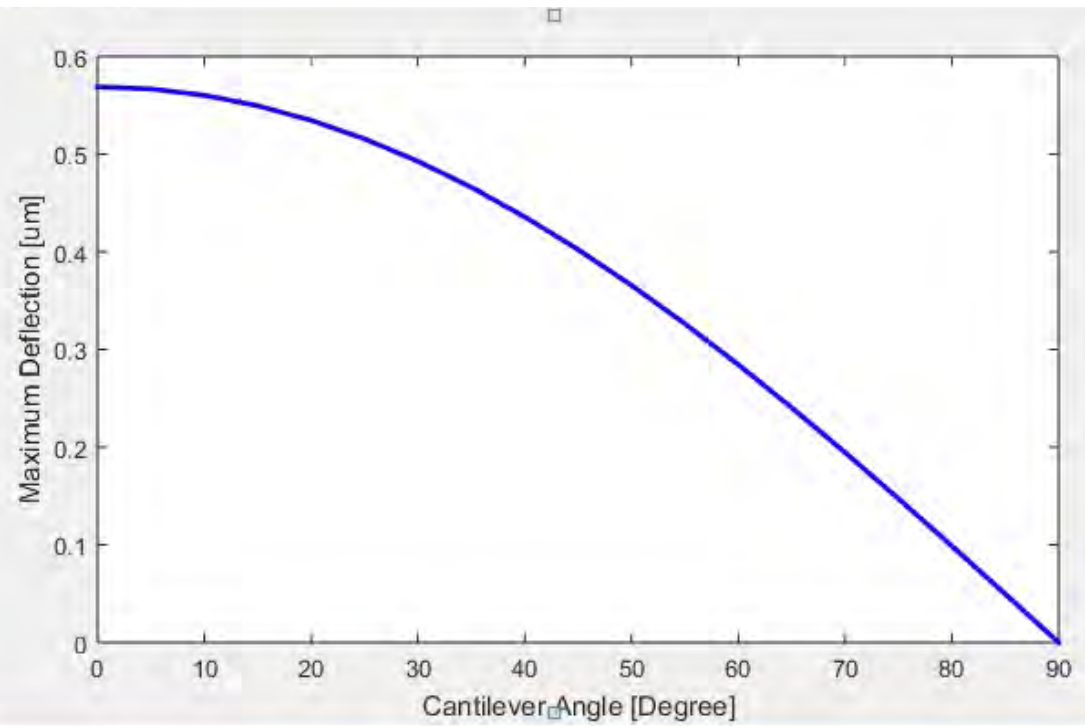

Figure 11: Effect of Cantilever Angle on Deflection.

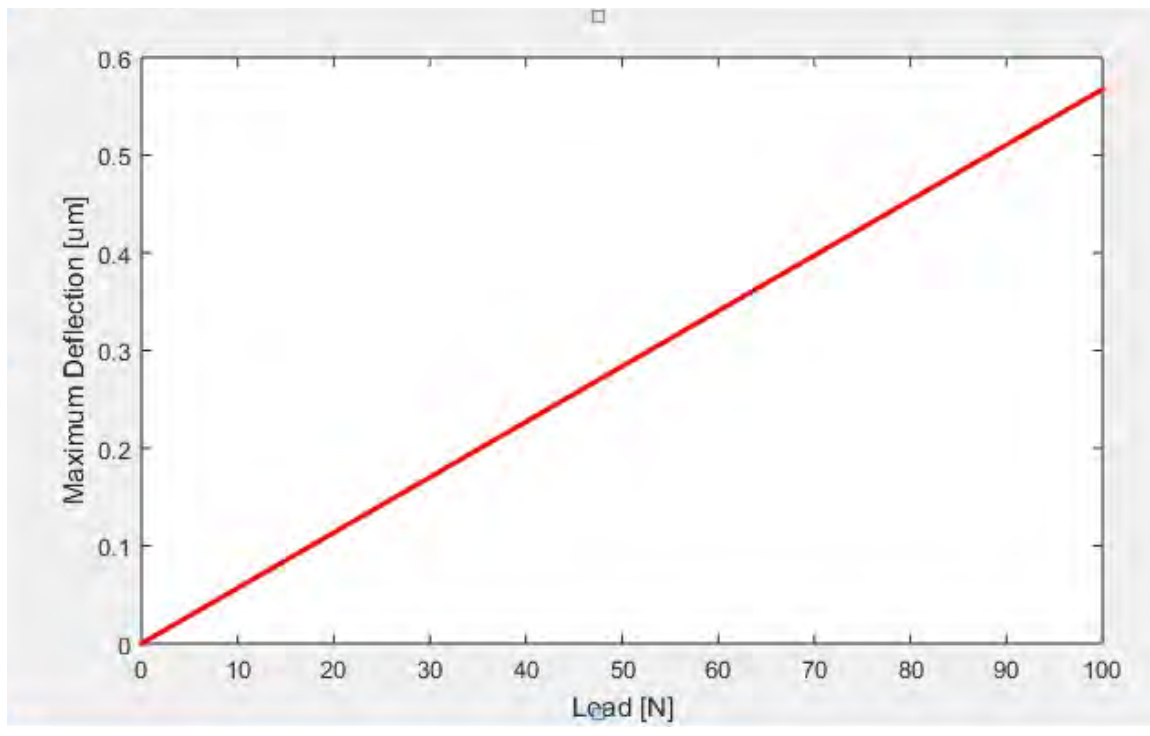

Figure 12: Effect of Load on Deflection. 


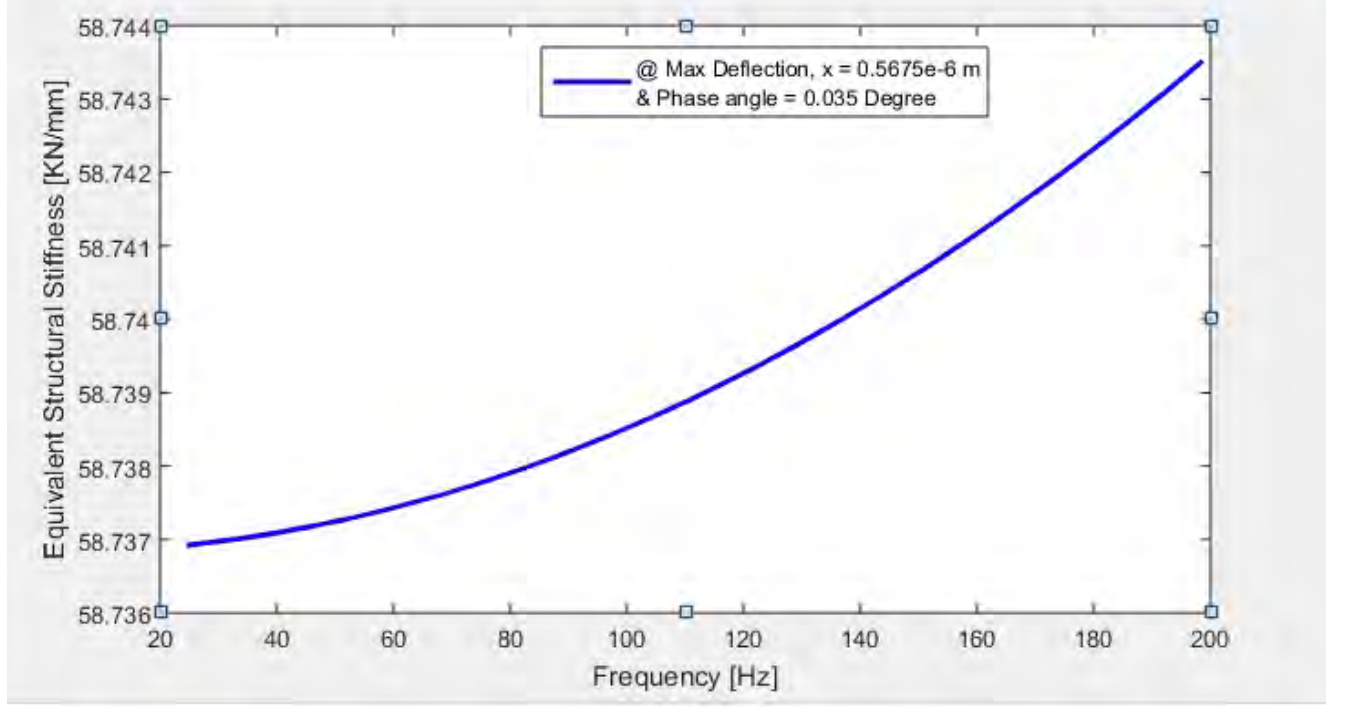

Figure 13: Effect of Frequency on Structural Stiffness.

Figure 13 shows an insignificant variation of equivalent structural stiffness and their frequencies. Theoretical structural stiffness is fairly constant at $58.74 \mathrm{kN} / \mathrm{mm}$ when determined at maximum deflection of $0.5675 \mathrm{~mm}$ and phase angle of 0.0350 . This represents the true structural stiffness of the foil strip-cantilever system because it agrees perfectly with the results obtained from structural models.

Figure 14 shows a significant variation of equivalent viscous damping coefficient with their frequencies. Theoretical viscous damping coefficient varies from $0.23 \mathrm{kNs} / \mathrm{m}$ at $24 \mathrm{~Hz}$ to $0.026 \mathrm{kNs} / \mathrm{m}$ at $200 \mathrm{~Hz}$ when determined at maximum deflection of $0.5675 \mathrm{~mm}$ and phase angle of 0.0350 . This means the higher the frequency, the lower the viscous damping coefficient [13].

Figure 15 depicts displacement-frequency plot. It shows vibration pattern. The figure shows that amplitude is constant at any frequency provided the load on the bearing and the time are not changed. The vibrating mass vibrates between $0.57 \mathrm{~mm}$ and $-0.28 \mathrm{~mm}$.

Figure 16 shows the effect of phase angle on the equivalent structural stiffness. The effect of phase angle was studied from assigned phase angle range of 0-6.28rad (0-3600). Eqs. (34) and (35) was used to re-compute the phase angle and their effect on equivalent structural stiffness and viscous damping coefficient. The graphs in Figures 16-18 are direct MATLAB output.

Figure 16(a) shows that maximum equivalent structural stiffness was obtained at phase angle values of 00,1800 (3.14rad) and 3600 (6.28rad). The equivalent structural stiffness becomes zero at $900(1.57 \mathrm{rad})$ and $2700(4.71 \mathrm{rad})$. Figure 16(b) shows the effect of calculated phase angle on structural stiffness. Eq. (35) only computes the acute angles from -900 (-1.57rad) to 900 (1.57rad), therefore, Figure 16(b) shows the stiffness curve within this range.

Equivalent stiffness increases with increase in deflection, that is, the structure of foil stripcantilever system becomes stiffer when in deflected position. Figure 18 shows maximum displacement at the point of maximum stiffness (i.e, $00,1800(3.14 \mathrm{rad})$ and 3600 (6.28rad)) and zero displacement at the point of zero stiffness (i.e, 900 (1.57rad) and 2700 (4.71rad). Figures 16 and 18 show that stiffness is maximum at points of maximum deflections and minimum at points of minimum deflections.

Figure 17 shows viscous damping acts in opposite direction to the direction of movement of the vibrating mass. It increases with decrease in deflection. Figure 17 shows minimum viscous damping coefficient at the points of maximum deflections (i.e., 00, 1800(3.14rad) and 3600 (6.28rad)) and maximum viscous damping coefficient at the points of minimum deflections (i.e, 900 (1.57rad) and 2700 (4.71rad).

\section{CONCLUSION}

This study gives an in-depth explanation to design analysis and performance evaluation of a novel multi-cantilever foil bearing (MCFB). The aim of this work is to develop a theoretical model to side-step the working principles of the cantilever foil bearing. Structural based modeling and vibration-based modeling of the multi-cantilever foil bearing was used to theoretically determine the equivalent structural stiffness, equivalent viscous damping coefficient and maximum deflection. Based on the investigation, following conclusions are drawn.

1. Findings show that the theoretical results of structural models show an equivalent structural stiffness of $58.59 \mathrm{kN} / \mathrm{mm}$, equivalent viscous damping of $0.599 \mathrm{kNs} / \mathrm{m}$ and maximum deflection of $0.5675 \mathrm{~mm}$.

2 . The results obtained from vibration models show an equivalent structural stiffness 


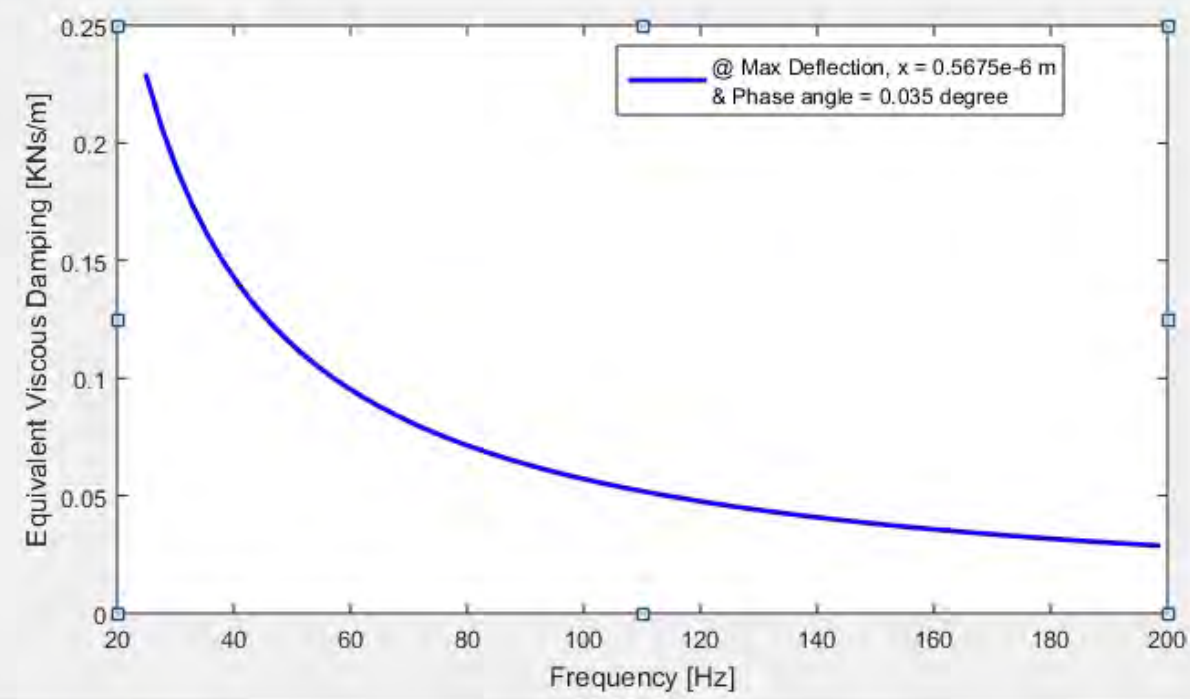

Figure 14: Effect of Frequency on Equivalent Viscous Damping.

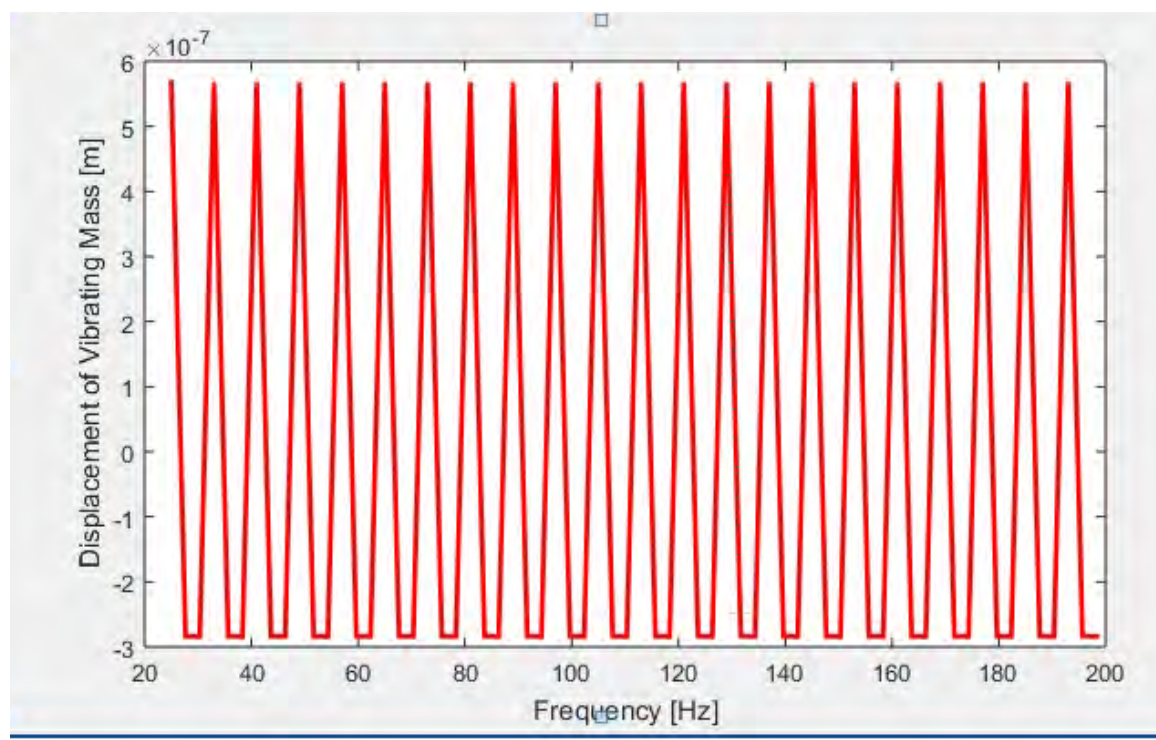

Figure 15: Displacement-Frequency Plot.
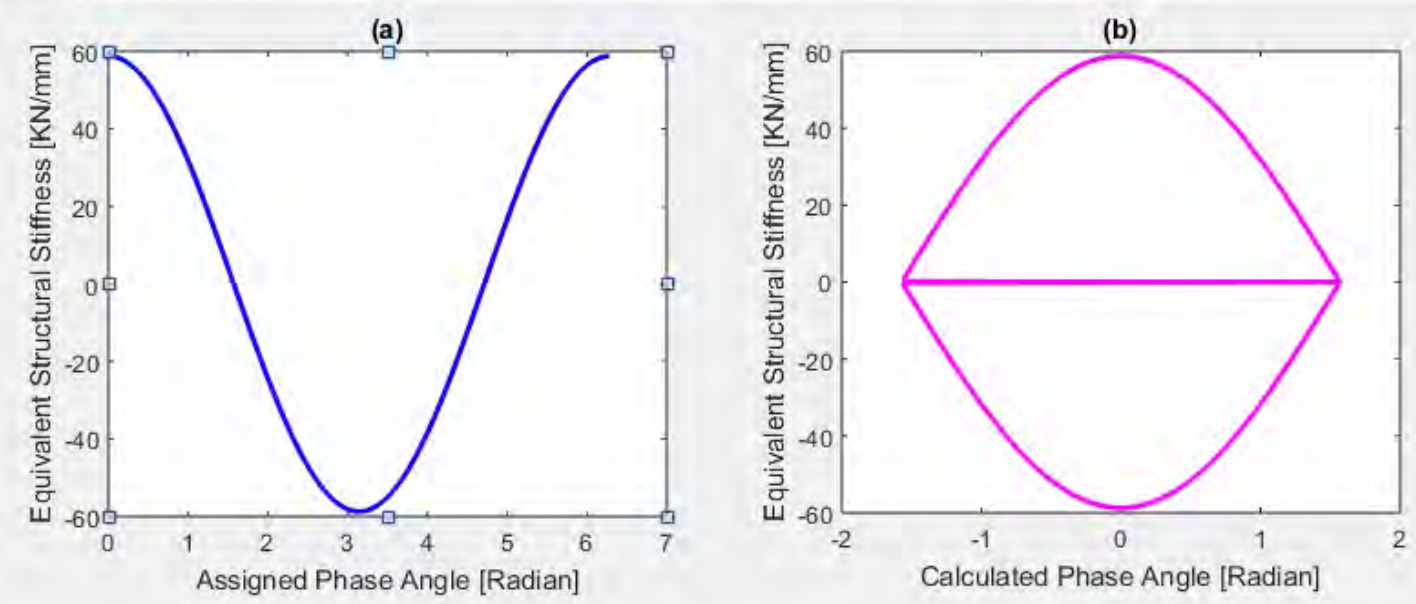

Figure 16: Effect of Phase Angle on Structural Stiffness. 
(a)

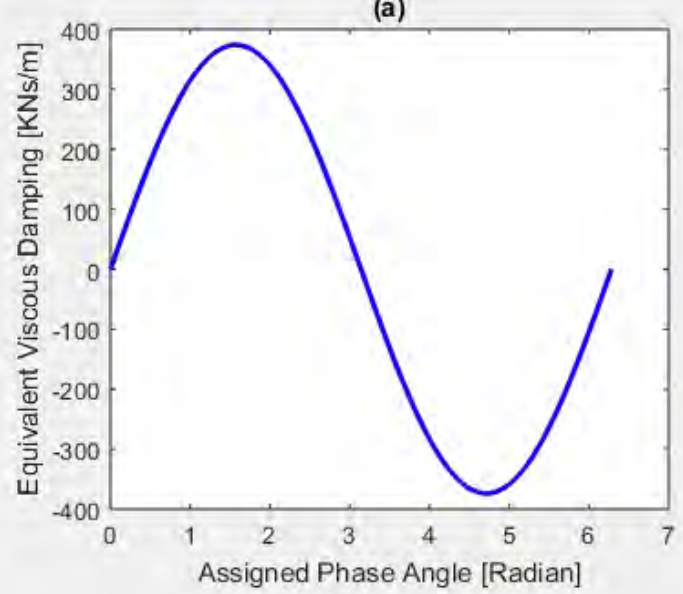

(b)

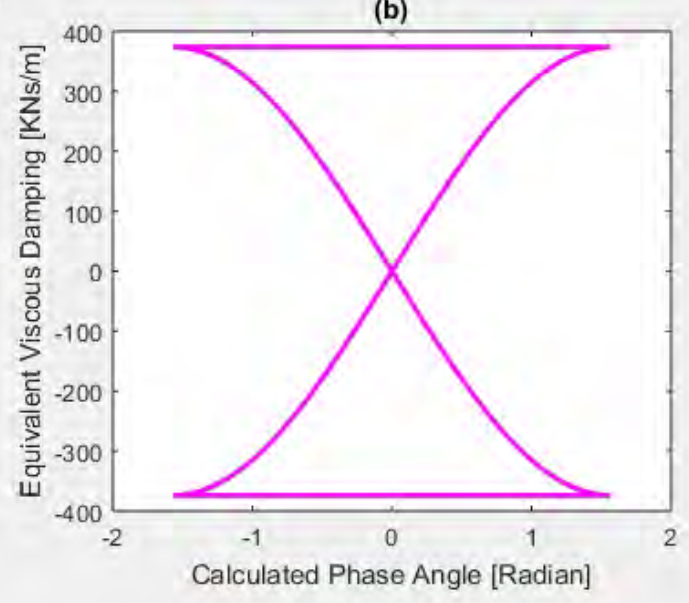

Figure 17: Effect of Phase Angle on Equivalent Viscous Damping.
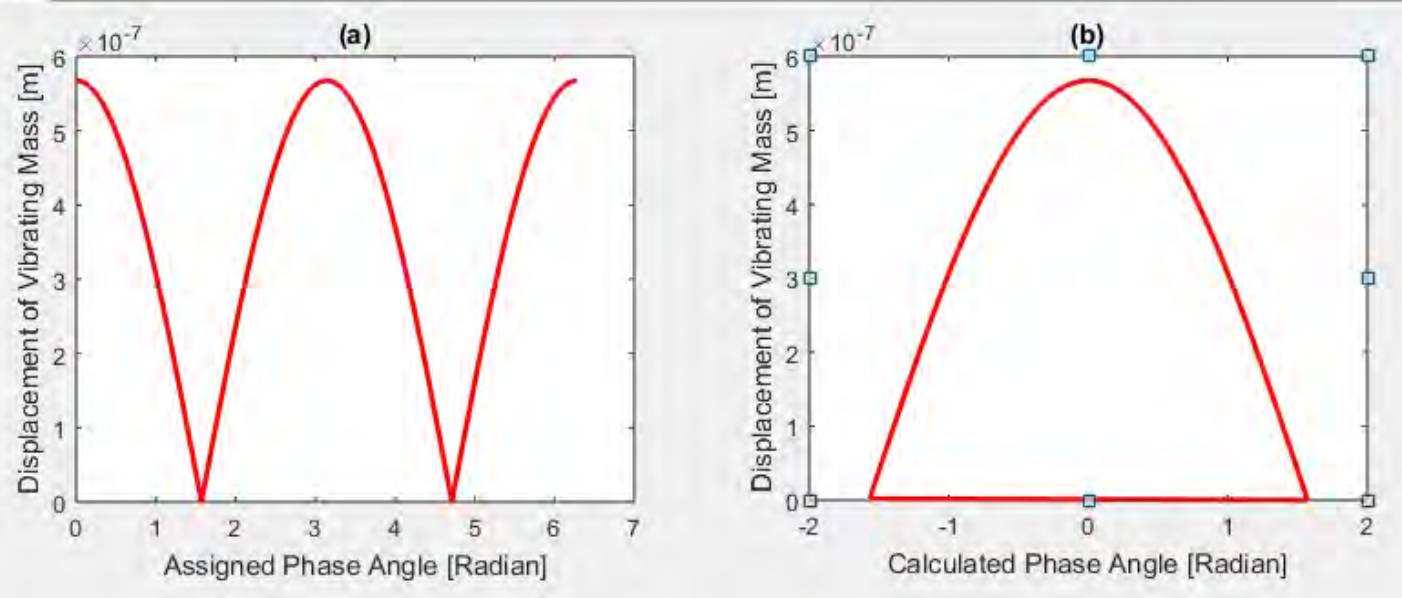

Figure 18: Effect of Phase Angle on Displacement.

of $58.74 \mathrm{kN} / \mathrm{mm}$, equivalent viscous damping of $0.228 \mathrm{kNs} / \mathrm{m}$ and maximum deflection of $0.5675 \mathrm{~mm}$.

3. In comparative analysis between the output values of structural model and vibration model, the models are in agreement especially in the determination of structural stiffness and maximum deflection.

4. Theoretical viscous damping coefficient varies from $0.23 \mathrm{kNs} / \mathrm{m}$ at $24 \mathrm{~Hz}$ to $0.026 \mathrm{kNs} / \mathrm{m}$ at $200 \mathrm{~Hz}$ when determined at maximum deflection of $0.5675 \mathrm{~mm}$ and phase angle of 0.0350 . This means the higher the frequency, the lower the viscous damping coefficient.

5. The validation was done over frequency range $24 \mathrm{~Hz}-200 \mathrm{~Hz}$ and at amplitude of $50 \mathrm{~mm}$ at a 450 phase angle. The theoretical models show a constant structural stiffness and maximum deflection over the range of frequencies under consideration.

The models were found to have compared well with experimental results in the prediction of equivalent viscous damping coefficient. The models can be relied upon to analyze the behaviour of MCFB and it can also form a theoretical background for the design and manufacture of MultiCantilever Foil Bearing.

\section{References}

[1] J. Wonbae, "Evaluation of coated top foil bearings: Drag friction coefficient, operating drag torque and lift-off speed, and dynamic force coefficients," Master's thesis, Office of Graduate and Professional Studies of Texas A\&M University, 2017.

[2] D. Christopher, "Stiffness and damping coefficient estimation of compliant surface gas bearings for oil-free turbo machinery," in International Joint Tribology Conference Cosponsored by the STLE and ASME, San Francisco, California, October 2010.

[3] Z. Grzegorz, L. Michal, and R. Jakub, "The effect of cooling the foil bearing on dynamics of the rotor-bearings system. jve international ltd," JVE International Ltd. Journal of Vibro Engineering, vol. 20, no. 2, pp. 1392$8716,2018$.

[4] D. Brian, "Factors influencing the performance of foil gas thrust bearings for oil free turbo machinery applications," Ph.D. dissertation, Case Western Reserve University, 2006.

[5] A. Serdar, "Coupled thermo-elastohydrodynamic analysis of a bump-type compliant foil journal bearing," Ph.D. dissertation, Engineering and Natural Sciences, Sabanci University, 2014. 
[6] Y. Hou, L. Xiong, and C. Chen, "Experimental study of a new compliant foil air bearing with elastic support," J. Tribology Transactions, vol. 47, no. 2, pp. 308-411, 2004.

[7] Y. Lee, C. Kim, J. Jo, and K. Ryu, "Air foils bearing having a porous foil,"U.S. Patent, 2008 , pub. No. US 2008/0310778 A1.

[8] G. Wang, S. Cheng, and H. Hao, "Recent progress in structural styles of journal foil gas bearings," in IOP Conference Series: Material Science and Engineering $439042016,2018$.

[9] S. Luis, A. Thomas, and T. Kim, "Measurement of structural stiffness and damping coefficients in a metal mesh foil bearing," Journal of Engineering for gas turbines and power, vol. 132, no. 032503, 2010.

[10] S. Chen, Y. Hou, L. Niu, S. Yang, and T. Lai, "Study on double-layer protuberant gas foil journal bearings with different foil layers arrangement," Journal of Advanced Mechanical Design, Systems, and Manufacturing, vol. 9, no. 2, pp. 34-58, 2015.

[11] K. Feng and S. Kaneko, "The numerical calculation of static performance of multi wound foil bearing and experimental validation," in ASME / STLE International Joint Tribology Conference, vol. 1, San Diego, California USA, October 2007, pp. 648-659.

[12] K. feng and S. Kaneko, "Thermo-hydrodynamic study of multi wound foil bearing using lobatto point quadrature." Journal of Tribology, vol. 131, no. 2, pp. 621-702, 2009.

[13] K. Feng, X. Zhao, and Z. Guo, "Design and structural performance measurements of a novel multi-cantilever foil bearing, Proceedings of the Institution of Mechanical Engineers, Part C:," Journal of Mechanical Engineering Science, SAGE, 2014.

[14] M. Obaseki and B. Alfred, "Modeling and investigating the effect of offset distance on slider-crank mechanism," Uniport journal of Engineering and Scientific Research, vol. 5, no. 2, pp. 82-95, 2020.

[15] T. Beléndez, C. Neipp, and A. Beléndez, "Large and small deflections of a cantilever beam," European Journal of Physics, vol. 23, no. 3, pp. 371-379, 2002.

[16] R. Rajput, Strength of Materials (Mechanics of Solids) in SI Units., ser. 261-271. Ram Nagar, New Delhi-110: S. Chand \& Company Ltd., 2010, vol. 110, no. 055.

[17] Z. Liu, Y. Wei, G. Wang, Y. Cong, and L. Chen, "Reaction torque of gas foil journal bearing with misalignment," Materials Science and Engineering, vol. 542, no. $012015,2019$.

[18] L. Tim, B. Christoph, and S. Wolfgang, "Computational analysis of foil air journal bearings using a runtimeefficient segmented foil model," International Symposium on Transport Phenomena and Dynamics of Rotating Machinery, April 2016, hawaii, Honolulu.

[19] S. S. Daniel, "Equivalent viscous damping," Lecture Notes, 2013 